\title{
Acetaminophen Hepatotoxicity
}

\author{
Anup Ramachandran, $\mathrm{PhD}^{1}$ Hartmut Jaeschke, $\mathrm{PhD}^{1}$ \\ ${ }^{1}$ Department of Pharmacology, Toxicology and Therapeutics, \\ University of Kansas Medical Center, Kansas City, Kansas \\ Semin Liver Dis 2019;39:221-234. \\ Address for correspondence Hartmut Jaeschke, PhD, Department of \\ Pharmacology, Toxicology and Therapeutics, University of Kansas \\ Medical Center, 3901 Rainbow Blvd, MS 1018, Kansas City, KS, 66160 \\ (e-mail: hjaeschke@kumc.edu).
}

\begin{abstract}
Keywords

- drug-induced liver injury

- apoptosis

- necroptosis

- mitochondrial dysfunction

- DNA fragmentation

- sterile inflammation

Acetaminophen (APAP) is one of the most popular and safe pain medications worldwide. However, due to its wide availability, it is frequently implicated in intentional or unintentional overdoses where it can cause severe liver injury and even acute liver failure (ALF). In fact, APAP toxicity is responsible for $46 \%$ of all ALF cases in the United States. Early mechanistic studies in mice demonstrated the formation of a reactive metabolite, which is responsible for hepatic glutathione depletion and initiation of the toxicity. This insight led to the rapid introduction of $\mathrm{N}$-acetylcysteine as a clinical antidote. However, more recently, substantial progress was made in further elucidating the detailed mechanisms of APAP-induced cell death. Mitochondrial protein adducts trigger a mitochondrial oxidant stress, which requires amplification through a MAPK cascade that ultimately results in activation of c-jun $\mathrm{N}$-terminal kinase (JNK) in the cytosol and translocation of phospho-JNK to the mitochondria. The enhanced oxidant stress is responsible for the membrane permeability transition pore opening and the membrane potential breakdown. The ensuing matrix swelling causes the release of intermembrane proteins such as endonuclease $G$, which translocate to the nucleus and induce DNA fragmentation. These pathophysiological signaling mechanisms can be additionally modulated by removing damaged mitochondria by autophagy and replacing them by mitochondrial biogenesis. Importantly, most of the mechanisms have been confirmed in human hepatocytes and indirectly through biomarkers in plasma of APAP overdose patients. The extensive necrosis caused by APAP overdose leads to a sterile inflammatory response. Although recruitment of inflammatory cells is necessary for removal of cell debris in preparation for regeneration, these cells have the potential to aggravate the injury. This review touches on the newest insight into the intracellular mechanisms of APAP-induced cells death and the resulting inflammatory response. Furthermore, it discusses the translation of these findings to humans and the emergence of new therapeutic interventions.
\end{abstract}

Available since the 1950s, acetaminophen (APAP, paracetamol) became one of the most used analgesic and antipyretic drugs worldwide. Although considered safe at therapeutic levels (4 g/day or less), overdoses can cause severe liver injury, which may even progress to acute liver failure (ALF). ${ }^{1}$ In fact, APAP hepatotoxicity is the most frequent cause of ALF of any etiology in the United States (46\%) and in most western countries (35-70\%). ${ }^{2,3}$ Patients who suffer from
APAP-induced liver injury either ingest a single overdose of 15 to $25 \mathrm{~g}$ in a suicide attempt or they end up with an unintentional overdose by taking therapeutic doses of multiple APAP-containing medications. ${ }^{3}$ This leads to well over 50,000 emergency department visits, 26,000 hospitalizations, and 450 deaths annually in the United States. ${ }^{4}$ Thus, APAP hepatotoxicity is a significant clinical problem.
Copyright (c) 2019 by Thieme Medical Publishers, Inc., 333 Seventh Avenue, New York, NY 10001, USA. Tel: +1(212) 584-4662.
DOI https://doi.org/ 10.1055/s-0039-1679919. ISSN 0272-8087. 
A controversial issue is whether therapeutic doses, which are 325 to $1,000 \mathrm{mg}$ every 6 hours according to the manufacturer's instructions, can cause liver injury in vulnerable patients ("therapeutic misadventure"). ${ }^{3,5}$ Based on the known mechanisms of toxicity, which includes the formation of a reactive metabolite by cytochrome $\mathrm{P} 450$ enzymes and its detoxification by glutathione (GSH), ${ }^{6}$ several risk factors are being considered. This includes use of drugs and herbal preparations that induce cytochrome P450 enzymes and enhance oxidative metabolism, malnutrition that lowers hepatic GSH levels and limits the defense against reactive metabolite formation, or genetic deficiency of phase II drug metabolizing enzymes. ${ }^{7,8}$ Although these risk factors need to be considered when taking APAP, there is limited evidence that this is actually a wide-spread problem. ${ }^{9}$ A more controversial issue is alcohol use. Acute alcohol ingestion directly competes with the oxidative metabolism of APAP and actually inhibits its toxicity. ${ }^{10}$ On the other hand, chronic alcohol consumption can induce Cyp2E1 enzyme activities and enhance the risk of APAP toxicity. ${ }^{11}$ However, clinical studies exposing chronic alcoholics to maximal therapeutic doses of APAP for one or several days did not result in any evidence of liver injury or liver dysfunction. ${ }^{12,13}$ Thus, there is limited evidence that therapeutic doses of APAP ( $\leq 4 \mathrm{~g} /$ day) can cause liver injury. However, these risk factors can lower the threshold when an overdose is causing liver injury and potentially worsen the outcome.

Early mechanistic investigations, which identified reactive metabolite formation and the defense of hepatic $\mathrm{GSH},{ }^{14}$ led to the rapid introduction of $\mathrm{N}$-acetylcysteine (NAC) as an antidote against APAP poisoning in the late 1970 s. ${ }^{15}$ Despite substantial progress in understanding the mechanism of toxicity in animal models and their verification of these mechanisms in humans, ${ }^{16}$ NAC is still the only clinically approved antidote. Although NAC can be very effective, especially when given very early after the overdose, there are also concerns of the limited efficacy in latepresenting patients ${ }^{17}$ or even adverse effects with prolonged treatment. ${ }^{18}$ Therefore, more detailed investigations are needed to better understand the mechanisms of cell death and recovery to identify relevant therapeutic targets that limit the injury and prevent ALF. This review will discuss established and controversial mechanisms and highlight recent efforts of translating the findings to the human pathophysiology and to the development of new drugs.

\section{Acetaminophen Metabolism}

Acetaminophen is rapidly absorbed from the intestine and transported to the liver, where it is mainly conjugated with glucuronic acid by the UDP-glucuronosyltransferase (UGT) 1A subfamily enzymes or sulfated by sulfotransferase enzymes at therapeutic doses, followed by excretion in the urine. ${ }^{6}$ While the sulfation reactions can be saturated at relatively low doses, ${ }^{19}$ glucuronidation reactions generally have a higher capacity and are apparently not saturated even after a severe overdose. ${ }^{20}$ However, several genetic polymorphisms in the UGT enzymes can affect APAP metabolism, where the UGT 1A polymorphism c.2042C > G (rs8330) was associated with increased human liver APAP glucuronidation, increased UGT1A exon 5a/5b splice variant mRNA ratio, and decreased risk of unintentional APAP-induced ALF. ${ }^{21}$ The UGT2B15*2 polymorphism was shown to influence APAP pharmacokinetics in both African Americans and European Americans. ${ }^{22}$ Neonates with the UGT1A9 $\mathrm{T}_{10}$ polymorphism, indicating insertion of an additional thymidine nucleotide, had a $42 \%$ reduction in clearance to APAP glucuronide as compared with their wild-type counterparts. ${ }^{23}$ Other factors could also influence glucuronidation, and miR-375 was identified as a novel repressor of UGT1A-mediated hepatic APAP glucuronidation through reduced aryl hydrocarbon receptor (AhR) expression, which could predispose some individuals to increased risk for APAP-induced ALF. ${ }^{24}$ Polymorphisms in sulfotransferases have also been shown to influence APAP metabolism. ${ }^{25}$ Even at therapeutic doses, a minor amount of APAP undergoes metabolism by the cytochrome P450 system, especially Cyp2E1 and Cyp1A2, producing the reactive metabolite $N$-acetyl- $p$-benzoquinone imine (NAPQI). ${ }^{6}$ This is generally not harmful, as NAPQI is efficiently scavenged by the abundant hepatic glutathione stores and excreted through bile. However, the situation is very different with an overdose of APAP, when the sulfation pathway is saturated. ${ }^{6}$ The excessive levels of APAP result in increased NAPQI formation, in spite of the fact that the glucuronidation pathway is not saturated. ${ }^{20}$ The elevated levels of highly reactive NAPQI deplete hepatic glutathione content and react with protein sulfhydryl groups, forming NAPQI-protein adducts. ${ }^{26}$ Recent evidence from in vitro experiments indicates that NAPQI can bind to and inhibit glutathione synthetase, catalyzing an essential step of glutathione synthesis. ${ }^{27}$ If this also occurs in vivo, it would have significant consequences, as inhibition of GSH synthesis by NAPQI would severely compromise detoxification of this reactive metabolite. However, given the efficacy of NAC to protect against an APAP overdose by stimulating GSH synthesis, the relevance of this effect may be limited. Protein adducts can form even at therapeutic doses ${ }^{6,26,28}$ indicating that extensive depletion of glutathione is not a prerequisite for adducts formation. Hence, currently available data seem to indicate that protein adducts formation per se does not always result in APAP-induced liver injury. This is illustrated by the effect of $\mathrm{N}$-acetyl-meta-aminophenol (AMAP), which is an analog of APAP and was shown to be nontoxic in mice ${ }^{29}$ and primary mouse hepatocytes. ${ }^{30}$ Interestingly, it was found that while both AMAP and APAP produced similar levels of total protein adducts, APAP produced significant mitochondrial adducts, while AMAP adducts were predominantly in other organelles. ${ }^{29,31}$ This implies that mitochondrial APAP-protein adducts are critical for liver injury, which was reiterated in more recent studies, which show that AMAP can actually be toxic in human liver slices ${ }^{32}$ as well as in isolated human hepatocytes due to formation of mitochondrial protein adducts and mitochondrial dysfunction, ${ }^{33}$ an effect absent in the mouse. ${ }^{29}$ 


\section{Mitochondrial Oxidative/Nitrosative Stress in APAP Hepatotoxicity}

Formation of mitochondrial APAP-protein adducts is now recognized to be a critical requirement for induction of downstream signaling events ultimately resulting in APAPinduced hepatocyte necrosis. Though several early studies interrogated the mitochondrial proteome to identify critical protein modifications responsible for downstream events, and found modifications on several of them, no single candidate functionally responsible for subsequent cell death could be identified. ${ }^{34}$ It is thus possible that rather than being modification of specific proteins, it could be a threshold of protein adducts within mitochondria that induce mitochondrial dysfunction and the cascade of subsequent cell signaling. A major consequence of APAP-induced mitochondrial protein adduct formation is enhanced generation of oxygen-free radicals, such as superoxide, ${ }^{35}$ inhibition of state 3 respiration, and decrease in the respiratory control ratio. ${ }^{36}$ The importance of this in mediating APAP-induced hepatotoxicity is illustrated by the protection provided by a mitochondrial targeted superoxide dismutase mimetic, Mito-TEMPO, ${ }^{37}$ as well as increased injury seen in partial manganese SOD-deficient animals. ${ }^{38,39}$ APAP-induced superoxide production within mitochondria can be influenced by several factors such as local oxygen tension, which is typically much lower within the liver than the $21 \%$ oxygen in room air. ${ }^{40}$ This influences APAP-induced superoxide production, since primary mouse hepatocytes cultured at $10 \%$ oxygen produced lower amounts of superoxide and had lower cell death in response to APAP when compared with cells cultured at room air (21\% oxygen). ${ }^{35}$ APAP was also shown to obstruct formation of mitochondrial respiratory super complexes by elevating the mitochondrial negative regulator $\mathrm{MCJ}$, which could then enhance reactive oxygen species (ROS) formation. ${ }^{41}$ Superoxide produced within mitochondria can react with nitric oxide to form peroxynitrite, which is highly reactive and can modify and modulate protein function. ${ }^{42}$ Peroxynitrite-derived radicals lead to the intermediate formation of tyrosyl radicals (Tyr ) on proteins, which then reacts at near diffusion-controlled rates with - $\mathrm{NO}_{2}$ to yield a stable final product, 3-nitrotyrosine on proteins, which interferes with protein function. ${ }^{42}$ Examination of 3-nitrotyrosine staining on liver sections after APAP overdose with $300 \mathrm{mg} / \mathrm{kg}$ in mice revealed significant elevations within liver mitochondria within an hour. ${ }^{43} 3$-Nitrotyrosine adducts were also visible in hepatocytes and sinusoidal endothelial cells at later time points. ${ }^{44,45}$ Mitochondrial generation of peroxynitrite seems to be critical for all downstream signaling events. ${ }^{43}$ It is, however, interesting to note that considering the $10-$ to $20 \mu \mathrm{M}$ concentrations of superoxide dismutase in mitochondria and the sub-micromolar levels of nitric oxide under normal conditions, it is surprising that peroxynitrite formation can occur in the face of overwhelming abundance of SOD, which would dismutate superoxide before it has a chance to react with nitric oxide. ${ }^{42}$ But constitutive generation of peroxynitrite does occur, and the key to this is the rate constant for the reaction of super- oxide with nitric oxide to yield peroxynitrite. ${ }^{42}$ This is one order of magnitude higher than that of SOD-catalyzed superoxide dismutation and upon sustained overactivation of nitric oxide synthase (NOS), NO will approach or exceed micromolar levels and will more efficiently compete with SOD, resulting in more significant fluxes of peroxynitrite. ${ }^{42}$ Thus, it is evident that elevations in peroxynitrite seen after APAP have to be accompanied by upregulation of NOS. Of the three main NOS isoforms, formation of peroxynitrite in the context of APAP overdose is independent of inducible NOS (iNOS) in vivo. ${ }^{45,46}$ Though mice deficient in endothelial NOS (eNOS) have been shown to have lower APAP-induced liver injury when compared with wild-type animals, ${ }^{47}$ the most prominent isoform of NOS involved in APAP hepatotoxicity seems to be neuronal NOS (nNOS). Direct pharmacological inhibition, ${ }^{48}$ or interference with calcium induction of nNOS, ${ }^{49}$ protected against APAP-induced cell death in primary mouse hepatocytes. These effects also seem to be relevant in vivo, since nNOS knockout mice were protected from APAP-induced liver injury. ${ }^{50}$ While nNOS has been identified in hepatocytes, ${ }^{51}$ it is unclear if it is localized to liver mitochondria. ${ }^{52}$ However, since NO can partition rapidly into lipid membranes,,$^{53}$ and hepatocytes have abundant mitochondria, it is plausible that upregulation of nNOS could elevate NO levels within mitochondria to levels that out-compete SOD for superoxide and form peroxynitrite. It is also interesting to note that in addition to damage to mitochondrial DNA in vivo, ${ }^{43}$ APAP-induced peroxynitrite formation also nitrated manganese SOD and inhibited its activity. ${ }^{54}$ This would then set the stage for amplification of peroxynitrite generation, which is a critical event influencing various downstream cell-signaling events. This is evident in the protection offered against APAP-induced liver injury by scavenging peroxynitrite with early glutathione supplementation, ${ }^{55}$ delayed GSH treatment, which also enhances regeneration; ${ }^{55,56}$ and preventing peroxynitrite formation by enhanced dismutation of superoxide ${ }^{37}$ or reduced formation of superoxide by inhibiting complex I. ${ }^{57}$

\section{Amplification of Mitochondrial Dysfunction and Downstream Signaling}

An important amplification step subsequent to APAPinduced mitochondrial oxidative/nitrosative stress is activation of the c-jun $\mathrm{N}$-terminal kinase (JNK) in the cytosol, which translocates to mitochondria, inducing mitochondrial dysfunction. ${ }^{46,58}$ Activation of JNK is a multistep process, involving several mediators such as the apoptosis signalregulating kinase 1 (ASK1), which is localized in both cytoplasm and mitochondria where it binds to cytosolic (Trx1) and mitochondrial thioredoxin (Trx2), respectively ${ }^{59}$ APAPinduced mitochondrial oxidative/nitrosative stress results in oxidation of thioredoxin within mitochondria, ${ }^{60}$ along with inhibition of both cytosolic TrxR1 and mitochondrial TrxR2 activity. ${ }^{61}$ This causes detachment of thioredoxin from its binding partner ASK1, and activated ASK1 then phosphorylates JNK in the cytosol. The role of ASK1 in this process is evidenced by the protection against APAP-induced JNK 
activation in mice treated with a small molecular inhibitor of ASK1 or mice deficient in ASK1. ${ }^{62,63}$ Another kinase implicated in JNK activation is the mixed-lineage kinase 3 (MLK3), which is also activated by oxidant stress during APAP hepatotoxicity in vivo. ${ }^{64}$ While it has been suggested that MLK3 is responsible for the early JNK activation with its activation prevented in MLK3 knockout mice, the protection was lost at higher ( $>5 \mathrm{mM}$ ) doses of APAP in vitro and it is unclear if protection would be sustained beyond 6 hours in vivo. ${ }^{64}$ MLK3 can phosphorylate and activate JNK through MKK4, a MAPK2 kinase. ${ }^{65}$ More recently, unc-51 like autophagy activating kinase (ULK1/2) was identified as another upstream kinase that contributes to JNK activation through phosphorylation of MKK4/7. ${ }^{66}$ Activation of JNK occurs early after APAP overdose, with a dose of $300 \mathrm{mg} / \mathrm{kg}$ resulting in JNK activation within 1 hour in the cytosol. ${ }^{62}$ In addition, glycogen synthase kinase-3 $\beta$ (GSK-3 $\beta$ ), a major regulator of glycogen synthase, has also been implicated in JNK activation after APAP. Translocation of cytosolic GSK-3 $\beta$ to the mitochondria has been demonstrated early after APAP overdose and silencing GSK-3 $\beta$ attenuated APAP-induced JNK activation and liver injury in vivo. ${ }^{67}$ Interestingly, GSK-3 $\beta$ inhibition also enhanced regeneration after APAP-induced liver injury. ${ }^{68}$ This early JNK activation has far reaching consequences, initiated by translocation of activated JNK from the cytosol to the mitochondria. ${ }^{58}$ In addition, activated JNK can also phosphorylate 14-3-3, a cytoplasmic anchor of Bax, resulting in Bax translocation to the mitochondria. ${ }^{69}$ This also occurs early after APAP overdose, on a similar time-scale as JNK translocation. ${ }^{70,71}$ Monomers of Bax have been shown to require the mitochondrial outer membrane receptor TOM22 for insertion into the mitochondrial outer membrane, and once integrated, mitochondrial Bax acts as a receptor for cytosolic Bax. ${ }^{72}$ Phospho-JNK on the other hand binds to the outer mitochondrial membrane protein Sab, ${ }^{73}$ which releases the protein tyrosine phosphatase nonreceptor type 6 (SHP1) from Sab and ultimately decreases mitochondrial respiration. ${ }^{74}$ Mitochondrial Sab seems to be required for sustained JNK activation up to 4 hours after APAP, since cytosolic activation tapered off by 1 hour and mitochondrial translocation was completely blocked in Sab-deficient mice treated with APAP. ${ }^{73}$ Translocation of JNK and Bax to the mitochondria seems to have complementary consequences, where the JNK translocation compromises mitochondrial respiration and amplifies the oxidant stress and nitrosative stress, while Bax does not seem to influence mitochondrial oxygen-free radical and peroxynitrite formation, ${ }^{70}$ but is probably necessary for the subsequent induction of the mitochondrial permeability transition detailed later. Interestingly, mitochondrial targeted interventions such as the SOD mimetic Mito-TEMPO or the antidiabetic drug metformin did not alter APAPinduced activation of JNK or its translocation to the mitochondria, but prevented mitochondrial dysfunction and amplification of the injury. ${ }^{37,57}$ This indicates that JNK translocation to mitochondria amplifies the oxidative/nitrosative stress, which subsequently results in mitochondrial dysfunction. It should be noted, however, that the JNK- induced effect on mitochondria is concentration dependent, with lower doses of APAP (150 mg/kg) in mice causing transient activation of JNK, with reversible mitochondrial permeability transition pore opening. ${ }^{75}$ In addition to the APAP-induced translocation to mitochondria of the various proteins listed earlier, the organelle also takes up cellular iron from lysosomes. ${ }^{76}$ While lysosomal iron release may be due, in part, to lysosomal instability seen after APAP overdose, ${ }^{77}$ iron uptake into mitochondria after APAP overdose is mediated by the calcium uniporter. ${ }^{78}$

\section{Consequences of APAP-Induced Mitochondrial Protein Translocation}

The translocation of GSK-3 $\beta$, JNK, Bax, and iron into the mitochondria has catastrophic consequences for mitochondrial function, with an amplification of oxidative and nitrosative stress, as well as loss of mitochondrial membrane potential and induction of the mitochondrial membrane permeability transition (MPT). While the MPT has been recognized to alter mitochondrial inner membrane permeability, resulting in the collapse of the membrane potential and the release of calcium and smaller metabolites below a $1.5-\mathrm{kDa}$ threshold, it is the subsequent rupture of the outer membrane, which releases proteins such as cytochrome $c$ and compromises mitochondrial function. ${ }^{79}$ Though various putative components of the MPT pore have been identified over the years, the complete molecular characterization of the pore is still incomplete since controversy exists on the relevance of the various identified components in different tissue types and disease contexts. ${ }^{79}$ One of the unambiguous regulatory components of the pore, however, is cyclophilin $\mathrm{D}$, which has been shown to prevent pore opening in several different contexts. ${ }^{80}$ The importance of the MPT to APAPinduced hepatotoxicity is hence evident by the modulation of cell death in cyclophilin D-deficient mice subjected to an APAP overdose. ${ }^{81}$ While inhibition of cyclophilin D provided partial protection against APAP-induced cell death in vitro, ${ }^{82}$ interestingly, cyclophilin D-deficient mice were only protected against a moderate overdose of $200 \mathrm{mg} / \mathrm{kg} \mathrm{APAP}{ }^{81}$ with no protection at higher doses of $600 \mathrm{mg} / \mathrm{kg}^{83}$ Additionally, it was also shown that a dose of $150 \mathrm{mg} / \mathrm{kg}$ APAP resulted in transient JNK activation and reversible MPT in mice, while a $300 \mathrm{mg} / \mathrm{kg}$ dose produced sustained JNK activation and irreversible MPT opening and loss of mitochondrial membrane potential. ${ }^{75}$ These effects suggest that induction of the MPT can be titrated by the dose of APAP, with irreversible mitochondrial damage only occurring if subsequent outer membrane rupture takes place. This can be facilitated by Bax translocation, which along with Bak can form pores on the outer mitochondrial membrane subsequent to the MPT. ${ }^{84}$ However, mice deficient in Bax, though protected initially, succumbed to APAP-induced liver injury at later time points, ${ }^{70}$ implicating additional, as yet, unidentified players mediating this final outer membrane rupture. Irrespective of the upstream mechanisms, irreversible induction of the MPT and rupture of the mitochondrial outer membrane results in release of several mitochondrial 
proteins into the cytosol. While the release of some, such as cytochrome c, compromises mitochondrial respiration and prevent recovery of mitochondrial function, others such as endonuclease $G$ and apoptosis-inducing factor (AIF) have further signaling roles to play. ${ }^{85,86}$ Once released from mitochondria, these proteins translocate into the nucleus by virtue of their nuclear localizing signal, ${ }^{87}$ and induce cleavage of nuclear DNA, resulting in DNA fragmentation and cellular necrosis (-Fig. 1). ${ }^{85,86}$

While a significant focus of study had been the role of the mitochondria in mediating cellular necrosis after APAP overdose, it is now becoming evident that the organelle also plays important roles in recovery after APAP overdose. Autophagy is a well-characterized cellular process involved in turnover of senescent and damaged cellular components and it was recognized that autophagy plays a relevant role in APAPinduced liver injury. Defective mitochondria are also removed by a similar process, dubbed mitophagy, and are also seen after APAP overdose. ${ }^{88,89}$ Inhibition of mitophagy was found to exacerbate APAP-induced hepatotoxicity, 88,90 illustrating its importance in facilitating liver recovery and regeneration subsequent to APAP-induced liver injury. In addition to this, recent evidence also indicates that induction of mitochondrial biogenesis is an important component of liver recovery after APAP overdose and delayed enhancement of mitochondrial biogenesis provided protection against late injury after APAP. ${ }^{91}$ Thus, mitochondria are central to the pathophysiology of APAP-induced hepatotoxicity, from being a target for NAPQI-protein adducts to being a platform for integration of signaling from MAP kinases and nitric oxide as well as cellular iron. Recent evidence is uncovering the effect of APAP concentration on titrating the nuanced induction of the MPT as well as the role of mitochondrial biogenesis and mitophagy in recovery and regeneration after APAP

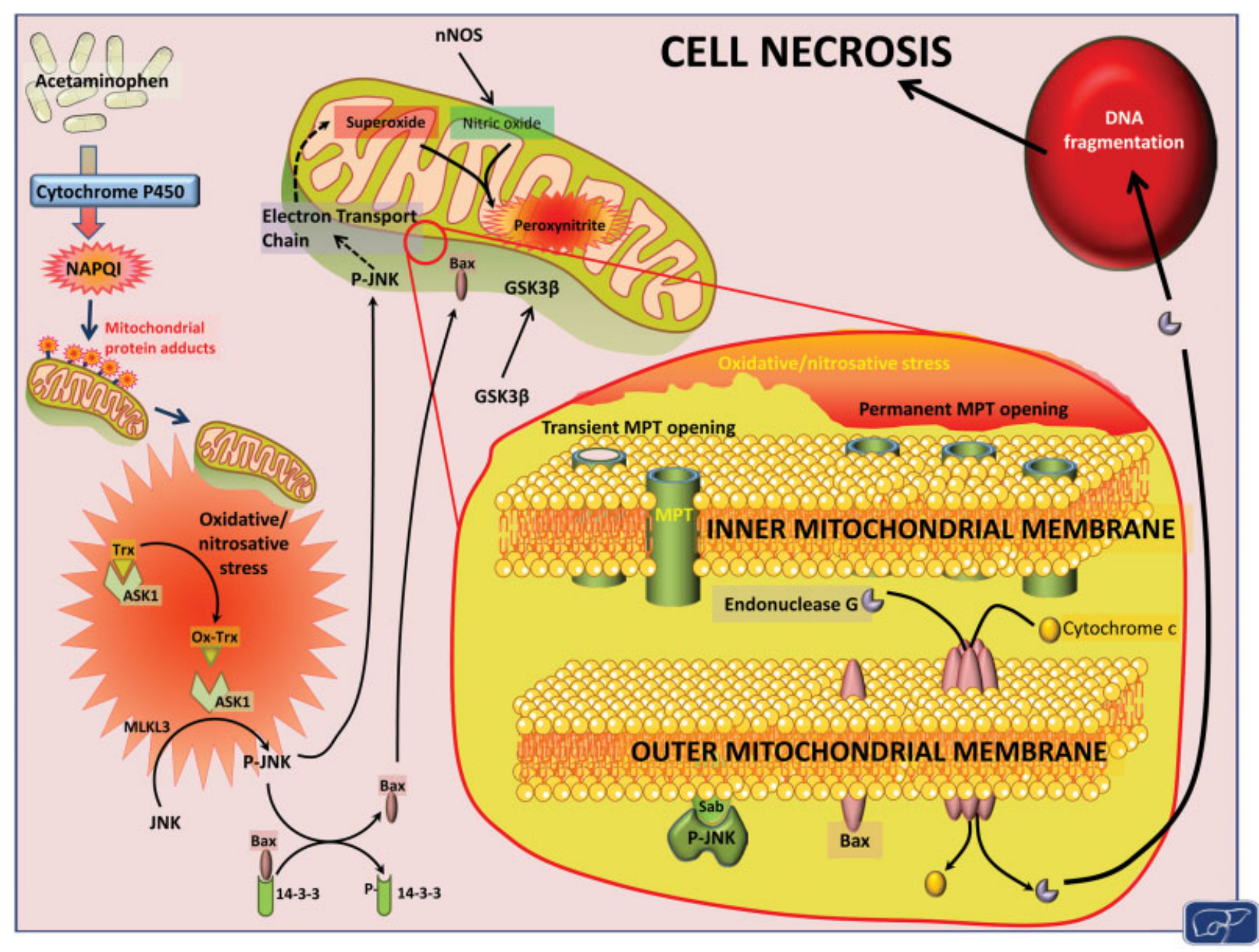

Fig. 1 Acetaminophen (APAP)-induced cell necrosis. APAP metabolism through the cytochrome P450 enzyme results in generation of the reactive metabolite NAPQI, which forms adducts on mitochondrial proteins. The subsequent oxidative/nitrosative stress activates ASK1, which, along with MLKL3 phosphorylates and activates JNK. P-JNK then releases Bax from its cytosolic tether 12-3-3 and both proteins along with GSK3 3 translocate to mitochondria. JNK binds to Sab on the outer mitochondrial membrane and initiates signaling which compromises mitochondrial electron transport and amplifies the oxidative stress as well as generation of peroxynitrite. These changes induce the activation of the mitochondrial permeability transition pore (MPT) transiently at lower APAP concentrations, and permanently at higher APAP levels. MPT activation, along with formation of Bax pores on the outer membrane, results in release of mitochondrial proteins such as endonuclease $G$, cytochrome c, and apoptosis inducing factor (AIF) into the cytosol. Endonuclease G and AIF translocate to nucleus and induce nuclear DNA fragmentation and subsequent cell necrosis. 
overdose, which, from the clinical perspective, is very relevant to patient prognosis.

In addition to mitochondrial defects, induction of the ER stress response also occurs during APAP overdose ${ }^{92}$ and this was exacerbated in transgenic mice expressing the hepatitis C virus structural proteins core, E1 and E2. ${ }^{60}$ Induction of ER stress could be a consequence of the APAP reactive metabolite, since arylating quinones were shown to induce endoplasmic reticulum (ER) stress by activating the pancreatic ER kinase (PERK) signaling pathway including elF2 $\alpha$, ATF4, and $\mathrm{C} / \mathrm{EBP}$ homologous protein (CHOP). ${ }^{93}$ Constitutive expression of the mammalian stress sensor IRE1a, which plays a role in ER stress, was shown to result in degradation of Cyp1a2 and Cyp2e1 mRNA as well as protection against APAP-induced hepatotoxicity, ${ }^{94}$ and recent studies indicate that inactivation of Sirtuin2 protects mice from APAPinduced liver injury, by alleviation of ER stress and phosphorylation of the p70 ribosomal S6 kinase 1 (S6K1). ${ }^{95}$ However, mice deficient in CHOP were not significantly protected against APAP hepatotoxicity, unless APAP was administered by gavage, ${ }^{92}$ suggesting that while ER stress is induced after APAP overdose, it may not be playing a central role in the signaling cascade of injury. Another factor which has been implicated in mediating APAP-induced liver injury is the tumor-suppressor p53, which has been suggested to play a protective role in APAP-induced liver injury through inhibiting JNK activation ${ }^{96}$ and by regulation of drug-metabolizing enzymes and transporter expression. ${ }^{97}$ Recent evidence also indicates that p53 plays a pleotropic role after APAP overdose, preventing progression of liver injury by maintenance of metabolic homeostasis as well as initiation of liver regeneration through proliferative signaling. 98

\section{Apoptosis and Programmed Necrosis}

Although early studies only considered APAP-induced injury as necrosis, the interest in intracellular signaling mechanisms of cell death led to suggestions that both apoptosis 99 and necroptosis ${ }^{100}$ might be involved. However, apoptotic cell death is characterized by distinguishable morphological characteristics including cell shrinkage, chromatin condensation and margination, and formation of apoptotic bodies. In addition, a specific biochemical feature of apoptosis is the activation of caspases as indicated by the cleavage of the proenzymes and the increased respective enzyme activities. Importantly, highly effective pan-caspase inhibitors protect against apoptotic cell death in models of TNF- or Fas-induced apoptosis. ${ }^{101,102}$ However, none of these morphological features of apoptosis are present in APAP-induced liver injury. ${ }^{103}$ Instead, there is cell and organelle swelling, cell contents release, and inflammation, all characteristics of necrosis. ${ }^{103}$ Furthermore, no relevant caspase processing and increase in enzyme activities can be observed during APAP hepatotoxicity and pan-caspase inhibitors do not protect when proper solvent control are being used. ${ }^{103-105}$ Thus, apoptosis is quantitatively not a relevant mode of cell death during APAP-induced liver injury in vitro or in vivo. ${ }^{106}$
However, given the overlap of some mechanistic aspects of apoptosis with APAP-induced liver injury such as mitochondrial Bax translocation, cytochrome c release, and nuclear DNA fragmentation, there are certain conditions where secondary apoptotic cell death may develop. One example is when APAP-induced necrotic cell death is blocked by inhibition of the MPT, though the initial stress from reactive metabolite formation and protein binding is still present. In this scenario, some cells, especially in culture, can die by apoptosis at a later stage. ${ }^{82}$ Nevertheless, more recently several articles are being published that make claims of apoptosis in APAP hepatotoxicity and suggest that phytochemicals may protect due to antiapoptotic mechanisms. ${ }^{107,108}$ However, as reviewed recently in detail, most of these studies base their conclusions on measurements of parameters that are not specific for apoptosis (e.g., TUNEL assay, as well as mRNA or protein levels of Bax, Bcl-2, and procaspases in the liver), rather than determination of their function (e.g., mitochondrial translocation of Bax or caspase- 3 enzyme activities). ${ }^{106}$ Thus, the claims of a relevant contribution of apoptosis are not supported by the experimental data.

More recently, necroptosis, another mode of cell death was discovered. Necroptosis occurs in cells when TNF- $\alpha$ binds to the TNF receptor in the presence of a pancaspase inhibitor. ${ }^{109}$ Under these conditions, the receptor-interacting protein kinase 1 (RIPK1) binds to RIPK3 and forms together with FADD the necrosome. ${ }^{110}$ RIPK3 oligomerizes and activates the pseudokinase mixed lineage kinase domain-like pseudokinase (MLKL). ${ }^{111}$ The phosphorylated form of MLKL translocates to the cell membrane and causes its permeabilization, which leads to cell death. ${ }^{112}$ Early experiments using the RIPK1 inhibitor necrostatin demonstrated a protective effect against APAP hepatotoxicity resulting in the conclusion that the mode of cell death is necroptosis. ${ }^{100}$ Further studies showed induction of hepatic RIPK3 expression after an APAP overdose; animals with RIPK3 gene knockdown and RIPK3-deficient mice were partially protected. ${ }^{113,114}$ In addition, a RIPK3 inhibitor attenuated APAP-induced cell death in a human hepatocyte cell line. ${ }^{115}$ The importance of RIPK1 in APAP toxicity was confirmed by gene knockdown experiments ${ }^{116}$ but also questioned by experiments with hepatocyte-specific RIPK1-deficient mice. ${ }^{117}$ Likewise, the data with RIPK3deficient mice were not confirmed. ${ }^{116}$ In addition, MLKLdeficient mice were not protected against APAP toxicity. ${ }^{116}$ Together, these data do not support the hypothesis that APAP-induced cell death is caused by necroptosis. More experiments are needed to better understand the role of RIP kinases in APAP hepatotoxicity including the mechanism of activation and their downstream targets.

\section{Relevance of Experimental APAP Toxicity Models for the Human Pathophysiology}

\section{Cells and Animal Models}

During the last $40+$ years, many studies using various experimental systems have been performed to investigate 
details of the mechanisms of APAP-induced cell death. Most frequently used models are mice in vivo and mouse hepatocytes. ${ }^{118}$ Almost all of the previously discussed mechanisms were investigated with mouse models, where the animals are typically fasted before treatment with APAP. This negates the effects of diurnal variations in Cyp2e1 and hepatic glutathione and results in more uniform toxicity in all treated mice. Rats and rat hepatocytes are in general considerably less sensitive to APAP toxicity despite extensive GSH depletion and even protein adduct formation in mitochondria. ${ }^{19-121}$ However, mitochondrial protein adducts were significantly lower in rats when compared with mice and hence they also had less oxidative stress as well as no detectable activation and mitochondrial translocation of JNK, ${ }^{119}$ which would explain the resistance to toxicity. Hence, the modest injury even after an excessive overdose and the limited mitochondrial dysfunction and oxidant stress suggests that the rat model is of limited relevance for the human disease. ${ }^{119}$ Other frequently used systems are hepatoma cells (e.g., HepG2 cells). However, these cells lack relevant phase I drug metabolizing enzymes ${ }^{122}$ and thus the capacity for reactive metabolite and protein adduct formation, which is the initiating event of the toxicity. As a consequence, all signaling mechanisms in these cells and the endpoint of toxicity (i.e., apoptosis) have to be considered with caution despite the fact that these are human cells. ${ }^{106}$ The only exception is HepaRG cells, which are metabolically competent and have a gene expression profile closer to primary hepatocytes. ${ }^{123}$ APAP treatment of these cells results in formation of reactive metabolites and causes GSH depletion, oxidant stress, mitochondrial dysfunction, and necrotic cell death with a time course similar to human APAP overdose patients. ${ }^{124}$ The fundamental advantage of these cells is that they are readily available and frozen differentiated cells can be ready within a week. The disadvantages include costs of the cells and that they are a mixture of hepatocytes and biliary epithelial cells derived from a single donor. On the other hand, the ultimately most relevant cell model is primary human hepatocytes. These cells reproduced most aspects of the cell death signaling pathways observed in mouse hepatocytes including the rapid GSH depletion, mitochondrial protein adducts formation, JNK activation and P-JNK translocation to the mitochondria, mitochondrial dysfunction, and cell necrosis. ${ }^{125}$ However, all events are delayed in human hepatocytes resulting in peak necrosis at 48 hours as compared with 12 hours in mouse hepatocytes but very similar to the time course of the liver injury observed in human APAP overdose patients. ${ }^{1,126}$ These findings indicate that mice in vivo and cultured mouse hepatocytes are the best experimental systems for modeling the human pathophysiology. Caveats to consider when using mice are the different susceptibilities of various mouse strains ${ }^{127}$ including substrains $^{128}$ to an APAP overdose. This is a particular issue for selecting the appropriate wild-type animals when using genedeficient mice. In addition, there is a pronounced gender difference in the response to a toxic dose of APAP between male and female mice, which appears to be linked to the recovery of hepatic GSH levels. ${ }^{129,130}$

\section{Biomarkers}

Despite the similarities in signaling mechanisms between mouse and human hepatocytes, it is still important to verify these mechanisms in humans. Because of the bleeding risk of ALF patients, biopsy material taken close to the period of actual liver injury is rarely available. Therefore, plasma biomarkers ("liquid biopsy") are the preferred approach to understand the in vivo mechanisms of injury in patients. Two types of biomarkers are being applied: mechanistic and predictive biomarkers. Important mechanistic biomarkers for APAP toxicity are protein adducts in plasma, ${ }^{131}$ which confirmed the formation of the reactive metabolite in humans. Because of the much longer plasma half-life of the adducts compared with APAP, adduct levels can be used to identify if the patient took an APAP overdose as the cause of liver injury even if the patient presents to the emergency department more than 24 hours after taking the drug. ${ }^{132}$ Currently, a point-of-care assay for protein adducts is being developed to assist ER physicians in the diagnosis of APAP poisoning. ${ }^{133}$ Additional mechanistic biomarkers that have been used to assess mitochondrial damage in patients include plasma levels of mitochondrial DNA (mtDNA), the mitochondrial matrix protein glutamate dehydrogenase (GLDH), and nuclear DNA fragments, which are indirect markers for mitochondrial dysfunction. ${ }^{126}$ All three biomarkers show a close correlation with ALT/AST release in APAP overdose patients and in mice. However, mtDNA and nDNA fragments are cleared faster than the enzymes. ${ }^{126}$ Importantly, in a murine model of furosemide toxicity, which includes hepatocellular necrosis without prominent mitochondrial damage, ${ }^{134}$ only plasma ALT levels increased substantially but not mtDNA or GLDH levels. ${ }^{126}$ These observations suggest that mtDNA, GLDH, and nDNA fragments are not just necrosis markers but indicate mitochondrial damage during APAP overdose, ${ }^{126}$ a mechanism that is consistent with the findings obtained in the mouse model. ${ }^{135}$ Previous studies have shown that plasma ALT and AST levels do not predict the clinical outcome of survival and recovery or ALF and death after APAP overdose in patients. ${ }^{136}$ In contrast, in a larger cohort of patients with APAP-induced liver injury, all three mechanistic biomarkers of mitochondrial injury showed a positive correlation with a negative outcome similar to those with the Model for End-Stage Liver Disease (MELD) score. ${ }^{137}$ Another mitochondrial injury marker is the mitochondrial matrix protein carbamoyl phosphate synthetase-1, which was detectable in serum of both mice and humans after APAP overdose. ${ }^{138}$ Other markers of mitochondrial dysfunction, even in the absence of cell death, are acyl-carnitines. Long chain fatty acids are transported into mitochondria for degradation through the carnitine shuttle and mitochondrial damage and dysfunction after APAP overdose in mice results in the accumulation of long chain acyl-carnitines in plasma. ${ }^{139,140}$ However, NAC treatment, which can support mitochondrial bioenergetics by converting NAC into Krebs cycle intermediates, ${ }^{141}$ suppresses the increase in acyl-carnitine levels during APAP hepatotoxicity and this is the likely reason for the much lower levels of these biomarkers observed in patients than in 
mice. ${ }^{140}$ Elevated acyl-carnitine levels are only detectable in patients before NAC treatment. ${ }^{142}$

Mechanistic biomarkers for the mode of cell death include full length cytokeratin-18 (CK-18), micro-RNA-122 (miR122), and high mobility group box-1 (HMGB1) protein, which all reflect mainly necrotic liver injury. All of these biomarkers increase dramatically in plasma after APAP overdose in mice and humans with a similar time course as ALT activities suggesting extensive necrotic cell death. ${ }^{136,143-145}$ In contrast, biomarkers for apoptosis such as the caspase-cleaved CK-18 levels ${ }^{136}$ or caspase- 3 activities in plasma ${ }^{126}$ show very limited evidence for apoptotic cell death in patients, which correlates well with observations in mice ${ }^{103}$ and in human hepatocytes. ${ }^{125}$

The initiation of regeneration after severe APAP-induced liver injury is a key mechanism that determines whether the injury is repaired and the patient survives or goes into ALF and potentially dies. ${ }^{146}$ Serum $\alpha$-fetoprotein (AFP), which is a marker of hepatocyte proliferation, is elevated during recovery and even predicts survival. ${ }^{147}$ Another potential serum regeneration marker is leukocyte cell-derived chemotaxin 2 (LECT2). Serum levels of LECT2 increase early during regeneration after partial hepatectomy in mice. ${ }^{148}$ In addition, LECT2 levels inversely correlated with serum ALT activities during $\mathrm{ALF}^{149}$ and preliminary data in APAP patients indicate that survivors had lower plasma levels of LECT2. ${ }^{150}$ However, a recent DILI study did not show consistent changes in LECT2. ${ }^{151}$ Thus, many of these regeneration markers need to be further evaluated before they can be used to reliably predict recovery after APAP overdose.

\section{Predictive Biomarkers}

Most of the discussed mechanistic biomarkers including mtDNA, GLDH, HMGB1, CK-18, and others were also used to predict outcome. ${ }^{136-138}$ Peak levels of all these biomarkers are useful and predict negative outcome better than peak ALT activities. However, the predictive capacity for these parameters applies only to the comparison of larger patient cohorts; the absolute values of any of these biomarkers in individual patients do not allow predicting the outcome due to the substantial overlap in the levels of these biomarkers. In addition, these parameters are time consuming to measure, which means that the information from these biomarkers will not be available in time to impact clinical decisions. Nevertheless, more work needs to be done to identify new and more specific biomarkers and improve the time of analysis.

Another way these biomarkers can be used is to predict the extent of the injury early after APAP overdose. Because of the delayed injury process in humans compared with mice, patients who present early to the emergency department may not show increased plasma ALT activities or INR values. In these cases, measurement of CK-18 or miR-122 indicated that these parameters are more sensitive than ALT/AST activities and can predict liver injury in these patients. ${ }^{152}$ In fact, a larger patient study provided strong evidence that elevations in plasma CK-18, miR-122, and HMGB1 identified later APAP hepatotoxicity on early admission of patients to the emergency department when plasma ALT activities were in the normal range. ${ }^{153}$ Although these biomarkers have the potential to improve clinical decision making, the caveat that currently prevents the use of these biomarkers is the time it takes to measure these parameters.

Profiles of micro-RNA levels in plasma have been evaluated during APAP hepatotoxicity especially in adults and in children. ${ }^{154-156}$ Although a large number of various microRNAs were shown to be elevated during APAP-induced liver injury compared with patients with no injury, whether these changes are specific for APAP toxicity or reflect a general response to liver injury remains to be investigated. In one study, patients with liver injury by APAP showed significant differences in some micro-RNA levels compared with similar liver injury caused by hypoxic hepatitis. ${ }^{154}$ This may be important as it is difficult to properly diagnose these patients due to their similarity in clinical presentation. In addition, some of the other biomarkers of mitochondrial damage (mtDNA, GLDH, nuclear DNA fragments) or necrotic cell death (CK-18, HMGB1, miR-122, ALT) showed no differences between these patient groups. ${ }^{157}$ Thus, micro-RNA profiles or individual micro-RNAs have the potential to improve diagnosis of APAP-induced liver injury and predict outcome if a point-of-care assay can be developed.

\section{Role of Sterile Inflammation in APAP Hepatotoxicity}

Due to the extensive necrotic cell death, APAP hepatotoxicity is characterized by a prototypical sterile inflammatory response. These mechanisms have been reviewed recently. ${ }^{158-160}$ Briefly, APAP-induced necrosis causes the release of damage-associated molecular patterns (DAMPs) including mtDNA, nuclear DNA fragments, HMGB1, ATP, and many others. DAMPs bind to pattern recognition receptors such as toll-like receptors (TLRs) on innate immune cells and cause the transcriptional activation of cytokines and chemokines. In addition, engagement of purinergic receptors with ATP will trigger the activation of the inflammasome and consequently caspase- 1 , which facilitates the processing of pro-IL-1 $\beta$ or pro-IL-18 into the active cytokine. The inflammatory mediators are mainly responsible for the activation and recruitment of neutrophils and monocyte-derived macrophages into the liver. Although there is little disagreement regarding the mechanisms of cytokine and chemokine formation and inflammatory cell recruitment in response to APAP-induced necrosis, the controversial question is whether these inflammatory cells aggravate the injury or are recruited to facilitate clean-up and regeneration. ${ }^{159}$

The default assumption of most studies investigating inflammatory injury mechanisms is that neutrophils and/ or monocyte-derived macrophages aggravate the initial injury. Although both neutrophils and monocytes are recruited into the liver during APAP toxicity in both mice $^{161,162}$ and in humans, ${ }^{163,164}$ extensive studies have shown that the injury mechanisms of these phagocytes critically depend on ROS in various models. ${ }^{165,166}$ However, mice deficient in NADPH oxidase activity ${ }^{163,167}$ or mice 
treated with effective inhibitors of this enzyme ${ }^{168}$ do not show a reduced oxidant stress or any protection against APAP toxicity. Likewise, animals deficient of CD18 or ICAM$1,{ }^{168,169}$ critical adhesion molecules for neutrophil recruitment and their adhesion-dependent oxidant stress, are not protected, nor are animals treated with antibodies against CD18. ${ }^{161}$ These data strongly argue against a neutrophilmediated injury. Furthermore, mice deficient in monocyte chemoattractant protein 1 (MCP1) or its receptor CCR2 are not protected, suggesting no active involvement of monocyte-derived macrophages in APAP-induced injury. ${ }^{162,170,171}$ Some studies appear to contradict these findings, ${ }^{172-174}$ but it is not always clear why opposite results are obtained with the same animals. ${ }^{172}$ However, the protection in mice treated with a neutropenia-inducing antibody 24 hours before APAP is caused by a preconditioning effect ${ }^{159,160}$ rather than the lack of neutrophils, as the same antibody is ineffective when given shortly after APAP. ${ }^{168}$ Thus, the evidence for a direct effect of neutrophils or macrophages in aggravating APAP hepatotoxicity is limited and many experiments argue against it. In contrast, these phagocytes are critical for the recovery. ${ }^{162,170,171}$ Importantly, clinical studies also seem to support the hypothesis that both neutrophils ${ }^{163}$ and monocyte-derived macrophages ${ }^{164}$ are pro-regenerative. However, since an increasing number of studies find a role of various cytokines in the pathophysiology of APAP-induced liver injury, ${ }^{175}$ alternative explanations to the cytotoxicity of innate immune cells need to be considered. An example is the role of IL-10, which has been shown to limit iNOS induction and therefore the cytotoxicity of peroxynitrite in APAP hepatotoxicity. ${ }^{176}$ In addition, IL-4 protects because it enhances hepatic GSH synthesis. ${ }^{177}$ Connecting the inflammatory mediators with intracellular mechanisms of injury or regeneration is an area that needs further investigations.

\section{Novel Therapeutic Approaches against APAP Hepatotoxicity}

With the increased understanding of the pathophysiology of APAP hepatotoxicity in animal models and in humans, many promising therapeutic targets have been identified. One of the most solidly verified molecular target involved in the toxicity is a mitochondrial oxidant and nitrosative stress. ${ }^{178}$ Mitochondria-targeted SOD mimetics are highly effective in preventing APAP hepatotoxicity in mice ${ }^{37}$ and this provides the rationale for the current clinical studies with a mitochondria-targeted SOD mimetic as a potential new antidote for APAP-induced liver injury and ALF. ${ }^{179}$ However, the relatively limited number of patients affected by APAP hepatotoxicity makes it difficult to recover the high costs of de novo drug development. Therefore, as in the case of NAC, repurposing of already FDA-approved drugs may be more realistic. Recently, 4methylpyrazole (Fomepizole), an antidote against methanol poisoning, has been shown to be highly effective against APAP-induced liver injury by inhibiting P450 enzyme when given early in mice and human hepato- cytes $^{180}$ or by inhibiting of JNK activation when administered after the drug metabolism phase. ${ }^{181}$ In addition, metformin, a first-line drug to treat type 2 diabetes mellitus, substantially attenuated APAP hepatotoxicity $^{57,182}$ mainly by inhibiting complex I-mediated superoxide formation. ${ }^{57}$ A caveat for any new drug is that it has to be beneficial in the presence of NAC, the current standard of care.

\section{Conclusion}

Acetaminophen is not only the most consumed pain medication but also the most studied and clinically most relevant hepatotoxic drug in the United States and many western countries. Mechanistic investigations have demonstrated the importance of the drug metabolism and many intracellular signaling mechanisms with a special focus on mitochondria, in the toxicity. The extensive necrosis is responsible for a sterile inflammatory response, which is critical for recovery but has also the potential to aggravate the injury. This is a controversial area. However, a better understanding of these inflammatory mechanisms holds the promise for discovering new therapeutic targets, especially for the transition from the injury to the regeneration phase.

\section{Conflicts of Interest}

The authors declare that there is no conflict of interest.

\section{References}

1 Larson AM. Acetaminophen hepatotoxicity. Clin Liver Dis 2007; 11(03):525-548, vi

2 Bernal W, Auzinger G, Dhawan A, Wendon J. Acute liver failure. Lancet 2010;376(9736):190-201

3 Lee WM. Acetaminophen (APAP) hepatotoxicity - Isn't it time for APAP to go away? J Hepatol 2017;67(06):1324-1331

4 Nourjah P, Ahmad SR, Karwoski C, Willy M. Estimates of acetaminophen (Paracetomal)-associated overdoses in the United States. Pharmacoepidemiol Drug Saf 2006;15(06):398-405

5 Zimmerman HJ, Maddrey WC. Acetaminophen (paracetamol) hepatotoxicity with regular intake of alcohol: analysis of instances of therapeutic misadventure. Hepatology 1995;22 (03):767-773

6 McGill MR, Jaeschke H. Metabolism and disposition of acetaminophen: recent advances in relation to hepatotoxicity and diagnosis. Pharm Res 2013;30(09):2174-2187

7 Bunchorntavakul C, Reddy KR. Acetaminophen-related hepatotoxicity. Clin Liver Dis 2013;17(04):587-607, viii

8 Lancaster EM, Hiatt JR, Zarrinpar A. Acetaminophen hepatotoxicity: an updated review. Arch Toxicol 2015;89(02):193-199

9 Rumack BH. Acetaminophen misconceptions. Hepatology 2004; 40(01):10-15

10 Sato C, Nakano M, Lieber CS. Prevention of acetaminopheninduced hepatotoxicity by acute ethanol administration in the rat: comparison with carbon tetrachloride-induced hepatoxicity. J Pharmacol Exp Ther 1981;218(03):805-810

11 Sato C, Matsuda Y, Lieber CS. Increased hepatotoxicity of acetaminophen after chronic ethanol consumption in the rat. Gastroenterology 1981;80(01):140-148

12 Kuffner EK, Dart RC, Bogdan GM, Hill RE, Casper E, Darton L. Effect of maximal daily doses of acetaminophen on the liver of alcoholic patients: a randomized, double-blind, placebo-controlled trial. Arch Intern Med 2001;161(18):2247-2252 
13 Kuffner EK, Green JL, Bogdan GM, et al. The effect of acetaminophen (four grams a day for three consecutive days) on hepatic tests in alcoholic patients-a multicenter randomized study. BMC Med 2007;5:13

14 Mitchell JR, Jollow DJ, Potter WZ, Gillette JR, Brodie BB. Acetaminophen-induced hepatic necrosis. IV. Protective role of glutathione. J Pharmacol Exp Ther 1973;187(01):211-217

15 Rumack BH, Bateman DN. Acetaminophen and acetylcysteine dose and duration: past, present and future. Clin Toxicol (Phila) 2012;50(02):91-98

16 Jaeschke H, Xie Y, McGill MR. Acetaminophen-induced liver injury: from animal models to humans. J Clin Transl Hepatol 2014;2(03):153-161

17 Smilkstein MJ, Knapp GL, Kulig KW, Rumack BH. Efficacy of oral $\mathrm{N}$-acetylcysteine in the treatment of acetaminophen overdose. Analysis of the national multicenter study (1976 to 1985). N Engl J Med 1988;319(24):1557-1562

18 Yang R, Miki K, He X, Killeen ME, Fink MP. Prolonged treatment with $\mathrm{N}$-acetylcystine delays liver recovery from acetaminophen hepatotoxicity. Crit Care 2009;13(02):R55

19 Gelotte CK, Auiler JF, Lynch JM, Temple AR, Slattery JT. Disposition of acetaminophen at 4,6 , and $8 \mathrm{~g} /$ day for 3 days in healthy young adults. Clin Pharmacol Ther 2007;81(06):840-848

20 Xie Y, McGill MR, Cook SF, et al. Time course of acetaminophenprotein adducts and acetaminophen metabolites in circulation of overdose patients and in HepaRG cells. Xenobiotica 2015;45 (10):921-929

21 Court MH, Freytsis M, Wang X, et al; Acute Liver Failure Study Group. The UDP-glucuronosyltransferase (UGT) 1A polymorphism c.2042C $>$ G (rs8330) is associated with increased human liver acetaminophen glucuronidation, increased UGT1A exon $5 \mathrm{a} /$ $5 \mathrm{~b}$ splice variant mRNA ratio, and decreased risk of unintentional acetaminophen-induced acute liver failure. J Pharmacol Exp Ther 2013;345(02):297-307

22 Court MH, Zhu Z, Masse G, et al. Race, gender, and genetic polymorphism contribute to variability in acetaminophen pharmacokinetics, metabolism, and protein-adduct concentrations in healthy African-American and European-American volunteers. J Pharmacol Exp Ther 2017;362(03):431-440

23 Linakis MW, Cook SF, Kumar SS, et al. Polymorphic expression of UGT1A9 is associated with variable acetaminophen glucuronidation in neonates: a population pharmacokinetic and pharmacogenetic study. Clin Pharmacokinet 2018;57(10):1325-1336

24 Papageorgiou I, Freytsis M, Court MH. Transcriptome association analysis identifies miR-375 as a major determinant of variable acetaminophen glucuronidation by human liver. Biochem Pharmacol 2016;117:78-87

25 Bairam AF, Rasool MI, Alherz FA, et al. Effects of human SULT1A3/ SULT1A4 genetic polymorphisms on the sulfation of acetaminophen and opioid drugs by the cytosolic sulfotransferase SULT1A3. Arch Biochem Biophys 2018;648:44-52

26 McGill MR, Lebofsky M, Norris HR, et al. Plasma and liver acetaminophen-protein adduct levels in mice after acetaminophen treatment: dose-response, mechanisms, and clinical implications. Toxicol Appl Pharmacol 2013;269(03):240-249

27 Walker V, Mills GA, Anderson ME, et al. The acetaminophen metabolite N-acetyl-p-benzoquinone imine (NAPQI) inhibits glutathione synthetase in vitro; a clue to the mechanism of 5oxoprolinuric acidosis? Xenobiotica 2017;47(02):164-175

28 Heard KJ, Green JL, James LP, et al. Acetaminophen-cysteine adducts during therapeutic dosing and following overdose. BMC Gastroenterol 2011;11:20

29 Tirmenstein MA, Nelson SD. Subcellular binding and effects on calcium homeostasis produced by acetaminophen and a nonhepatotoxic regioisomer, 3'-hydroxyacetanilide, in mouse liver.J Biol Chem 1989;264(17):9814-9819

30 Holme JA, Hongslo JK, Bjørge C, Nelson SD. Comparative cytotoxic effects of acetaminophen (N-acetyl-p-aminophenol), a non-hepatotoxic regioisomer acetyl-m-aminophenol and their postulated reactive hydroquinone and quinone metabolites in monolayer cultures of mouse hepatocytes. Biochem Pharmacol 1991;42(05):1137-1142

31 Qiu Y, Benet LZ, Burlingame AL. Identification of hepatic protein targets of the reactive metabolites of the non-hepatotoxic regioisomer of acetaminophen, 3'-hydroxyacetanilide, in the mouse in vivo using two-dimensional gel electrophoresis and mass spectrometry. Adv Exp Med Biol 2001;500:663-673

32 Hadi M, Dragovic S, van Swelm R, et al. AMAP, the alleged nontoxic isomer of acetaminophen, is toxic in rat and human liver. Arch Toxicol 2013;87(01):155-165

33 Xie Y, McGill MR, Du K, et al. Mitochondrial protein adducts formation and mitochondrial dysfunction during N-acetyl-maminophenol (AMAP)-induced hepatotoxicity in primary human hepatocytes. Toxicol Appl Pharmacol 2015;289(02):213-222

34 Ramachandran A, Duan L, Akakpo J, Jaeschke H. Mitochondrial dysfunction as a mechanism of drug-induced hepatotoxicity: current understanding and future perspectives. J Clin Translational Res 2018;4(01):75-100

35 Yan HM, Ramachandran A, Bajt ML, Lemasters JJ, Jaeschke H. The oxygen tension modulates acetaminophen-induced mitochondrial oxidant stress and cell injury in cultured hepatocytes. Toxicol Sci 2010;117(02):515-523

36 Meyers LL, Beierschmitt WP, Khairallah EA, Cohen SD. Acetaminophen-induced inhibition of hepatic mitochondrial respiration in mice. Toxicol Appl Pharmacol 1988;93(03):378-387

37 Du K, Farhood A, Jaeschke H. Mitochondria-targeted antioxidant Mito-Tempo protects against acetaminophen hepatotoxicity. Arch Toxicol 2017;91(02):761-773

38 Ramachandran A, Lebofsky M, Weinman SA, Jaeschke H. The impact of partial manganese superoxide dismutase (SOD2)deficiency on mitochondrial oxidant stress, DNA fragmentation and liver injury during acetaminophen hepatotoxicity. Toxicol Appl Pharmacol 2011;251(03):226-233

39 Fujimoto K, Kumagai K, Ito K, et al. Sensitivity of liver injury in heterozygous Sod2 knockout mice treated with troglitazone or acetaminophen. Toxicol Pathol 2009;37(02):193-200

40 Kietzmann T, Jungermann K. Modulation by oxygen of zonal gene expression in liver studied in primary rat hepatocyte cultures. Cell Biol Toxicol 1997;13(4-5):243-255

41 Barbier-Torres L, Iruzubieta P, Fernández-Ramos D, et al. The mitochondrial negative regulator $\mathrm{MCJ}$ is a therapeutic target for acetaminophen-induced liver injury. Nat Commun 2017;8(01): 2068

42 Radi R. Oxygen radicals, nitric oxide, and peroxynitrite: redox pathways in molecular medicine. Proc Natl Acad Sci U S A 2018; 115(23):5839-5848

43 Cover C, Mansouri A, Knight TR, et al. Peroxynitrite-induced mitochondrial and endonuclease-mediated nuclear DNA damage in acetaminophen hepatotoxicity. J Pharmacol Exp Ther 2005;315(02):879-887

44 Hinson JA, Pike SL, Pumford NR, Mayeux PR. Nitrotyrosineprotein adducts in hepatic centrilobular areas following toxic doses of acetaminophen in mice. Chem Res Toxicol 1998;11(06): 604-607

45 Knight TR, Kurtz A, Bajt ML, Hinson JA, Jaeschke H. Vascular and hepatocellular peroxynitrite formation during acetaminophen toxicity: role of mitochondrial oxidant stress. Toxicol Sci 2001; 62(02):212-220

46 Saito C, Lemasters JJ, Jaeschke H. c-Jun N-terminal kinase modulates oxidant stress and peroxynitrite formation independent of inducible nitric oxide synthase in acetaminophen hepatotoxicity. Toxicol Appl Pharmacol 2010;246(1-2):8-17

47 Salhanick SD, Orlow D, Holt DE, Pavlides S, Reenstra W, Buras JA. Endothelially derived nitric oxide affects the severity of early acetaminophen-induced hepatic injury in mice. Acad Emerg Med 2006;13(05):479-485 
48 Banerjee S, Melnyk SB, Krager KJ, et al. The neuronal nitric oxide synthase inhibitor NANT blocks acetaminophen toxicity and protein nitration in freshly isolated hepatocytes. Free Radic Biol Med 2015;89:750-757

49 Banerjee S, Melnyk SB, Krager KJ, et al. Trifluoperazine inhibits acetaminophen-induced hepatotoxicity and hepatic reactive nitrogen formation in mice and in freshly isolated hepatocytes. Toxicol Rep 2017;4:134-142

50 Agarwal R, Hennings L, Rafferty TM, et al. Acetaminopheninduced hepatotoxicity and protein nitration in neuronal nitric-oxide synthase knockout mice. J Pharmacol Exp Ther 2012;340(01):134-142

51 Villanueva C, Giulivi C. Subcellular and cellular locations of nitric oxide synthase isoforms as determinants of health and disease. Free Radic Biol Med 2010;49(03):307-316

52 Lacza Z, Snipes JA, Zhang J, et al. Mitochondrial nitric oxide synthase is not eNOS, nNOS or iNOS. Free Radic Biol Med 2003;35 (10):1217-1228

53 Bartesaghi S, Radi R. Fundamentals on the biochemistry of peroxynitrite and protein tyrosine nitration. Redox Biol 2018; 14:618-625

54 Agarwal R, MacMillan-Crow LA, Rafferty TM, et al. Acetaminophen-induced hepatotoxicity in mice occurs with inhibition of activity and nitration of mitochondrial manganese superoxide dismutase. J Pharmacol Exp Ther 2011;337(01):110-116

55 Knight TR, Ho YS, Farhood A, Jaeschke H. Peroxynitrite is a critical mediator of acetaminophen hepatotoxicity in murine livers: protection by glutathione. J Pharmacol Exp Ther 2002;303 (02):468-475

56 Bajt ML, Knight TR, Farhood A, Jaeschke H. Scavenging peroxynitrite with glutathione promotes regeneration and enhances survival during acetaminophen-induced liver injury in mice. J Pharmacol Exp Ther 2003;307(01):67-73

57 Du K, Ramachandran A, Weemhoff JL, et al. Editor's highlight: metformin protects against acetaminophen hepatotoxicity by attenuation of mitochondrial oxidant stress and dysfunction. Toxicol Sci 2016;154(02):214-226

58 Hanawa N, Shinohara M, Saberi B, Gaarde WA, Han D, Kaplowitz N. Role of JNK translocation to mitochondria leading to inhibition of mitochondria bioenergetics in acetaminophen-induced liver injury. J Biol Chem 2008;283(20):13565-13577

59 Zhang R, Al-Lamki R, Bai L, et al. Thioredoxin-2 inhibits mitochondria-located ASK1-mediated apoptosis in a JNK-independent manner. Circ Res 2004;94(11):1483-1491

60 Ramachandran A, Lebofsky M, Yan HM, Weinman SA, Jaeschke H. Hepatitis $C$ virus structural proteins can exacerbate or ameliorate acetaminophen-induced liver injury in mice. Arch Toxicol 2015;89(05):773-783

61 Jan YH, Heck DE, Dragomir AC, Gardner CR, Laskin DL, Laskin JD. Acetaminophen reactive intermediates target hepatic thioredoxin reductase. Chem Res Toxicol 2014;27(05):882-894

62 Xie Y, Ramachandran A, Breckenridge DG, et al. Inhibitor of apoptosis signal-regulating kinase 1 protects against acetaminophen-induced liver injury. Toxicol Appl Pharmacol 2015;286 (01):1-9

63 Nakagawa H, Maeda S, Hikiba Y, et al. Deletion of apoptosis signal-regulating kinase 1 attenuates acetaminophen-induced liver injury by inhibiting c-Jun $\mathrm{N}$-terminal kinase activation. Gastroenterology 2008;135(04):1311-1321

64 Sharma M, Gadang V, Jaeschke A. Critical role for mixed-lineage kinase 3 in acetaminophen-induced hepatotoxicity. Mol Pharmacol 2012;82(05):1001-1007

65 Zhang J, Min RWM, Le K, et al. The role of MAP2 kinases and p38 kinase in acute murine liver injury models. Cell Death Dis 2017;8 (06): 22903

66 Sun Y, Li TY, Song L, et al. Liver-specific deficiency of unc-51 like kinase 1 and 2 protects mice from acetaminophen-induced liver injury. Hepatology 2018;67(06):2397-2413
67 Shinohara M, Ybanez MD, Win S, et al. Silencing glycogen synthase kinase-3beta inhibits acetaminophen hepatotoxicity and attenuates JNK activation and loss of glutamate cysteine ligase and myeloid cell leukemia sequence 1. J Biol Chem 2010; 285(11):8244-8255

68 Bhushan B, Poudel S, Manley MW Jr, Roy N, Apte U. Inhibition of glycogen synthase kinase 3 accelerated liver regeneration after acetaminophen-induced hepatotoxicity in mice. Am J Pathol 2017;187(03):543-552

69 Tsuruta F, Sunayama J, Mori Y, et al. JNK promotes Bax translocation to mitochondria through phosphorylation of 14-3-3 proteins. EMBO J 2004;23(08):1889-1899

70 Bajt ML, Farhood A, Lemasters JJ, Jaeschke H. Mitochondrial bax translocation accelerates DNA fragmentation and cell necrosis in a murine model of acetaminophen hepatotoxicity. J Pharmacol Exp Ther 2008;324(01):8-14

71 El-Hassan H, Anwar K, Macanas-Pirard P, et al. Involvement of mitochondria in acetaminophen-induced apoptosis and hepatic injury: roles of cytochrome c, Bax, Bid, and caspases. Toxicol Appl Pharmacol 2003;191(02):118-129

72 Cartron PF, Bellot G, Oliver L, Grandier-Vazeille X, Manon S, Vallette FM. Bax inserts into the mitochondrial outer membrane by different mechanisms. FEBS Lett 2008;582(20):3045-3051

73 Win S, Than TA, Han D, Petrovic LM, Kaplowitz N. c-Jun Nterminal kinase (JNK)-dependent acute liver injury from acetaminophen or tumor necrosis factor (TNF) requires mitochondrial Sab protein expression in mice. J Biol Chem 2011;286(40): 35071-35078

74 Win S, Than TA, Min RW, Aghajan M, Kaplowitz N. c-Jun Nterminal kinase mediates mouse liver injury through a novel Sab (SH3BP5)-dependent pathway leading to inactivation of intramitochondrial Src. Hepatology 2016;63(06):1987-2003

$75 \mathrm{Hu}$ J, Ramshesh VK, McGill MR, Jaeschke H, Lemasters JJ. Low dose acetaminophen induces reversible mitochondrial dysfunction associated with transient $\mathrm{c}$-jun $\mathrm{N}$-terminal kinase activation in mouse liver. Toxicol Sci 2016;150(01):204-215

76 Kon K, Kim JS, Uchiyama A, Jaeschke H, Lemasters JJ. Lysosomal iron mobilization and induction of the mitochondrial permeability transition in acetaminophen-induced toxicity to mouse hepatocytes. Toxicol Sci 2010;117(01):101-108

77 Woolbright BL, Ramachandran A, McGill MR, et al. Lysosomal instability and cathepsin $B$ release during acetaminophen hepatotoxicity. Basic Clin Pharmacol Toxicol 2012;111(06):417-425

$78 \mathrm{Hu}$ J, Kholmukhamedov A, Lindsey CC, Beeson CC, Jaeschke H, Lemasters JJ. Translocation of iron from lysosomes to mitochondria during acetaminophen-induced hepatocellular injury: protection by Starch-Desferal and minocycline. Free Radic Biol Med 2016;97:418-426

79 Baines CP, Gutiérrez-Aguilar M. The still uncertain identity of the channel-forming unit(s) of the mitochondrial permeability transition pore. Cell Calcium 2018;73:121-130

80 Baines CP, Kaiser RA, Purcell NH, et al. Loss of cyclophilin D reveals a critical role for mitochondrial permeability transition in cell death. Nature 2005;434(7033):658-662

81 Ramachandran A, Lebofsky M, Baines CP, Lemasters JJ, Jaeschke $\mathrm{H}$. Cyclophilin D deficiency protects against acetaminopheninduced oxidant stress and liver injury. Free Radic Res 2011;45 (02):156-164

82 Kon K, Kim JS, Jaeschke H, Lemasters JJ. Mitochondrial permeability transition in acetaminophen-induced necrosis and apoptosis of cultured mouse hepatocytes. Hepatology 2004;40(05): 1170-1179

83 LoGuidice A, Boelsterli UA. Acetaminophen overdose-induced liver injury in mice is mediated by peroxynitrite independently of the cyclophilin D-regulated permeability transition. Hepatology 2011;54(03):969-978

84 Karch J, Kwong JQ, Burr AR, et al. Bax and Bak function as the outer membrane component of the mitochondrial permeability 
pore in regulating necrotic cell death in mice. eLife 2013;2: e00772

85 Bajt ML, Cover C, Lemasters JJ, Jaeschke H. Nuclear translocation of endonuclease $\mathrm{G}$ and apoptosis-inducing factor during acetaminophen-induced liver cell injury. Toxicol Sci 2006;94(01): 217-225

86 Bajt ML, Ramachandran A, Yan HM, et al. Apoptosis-inducing factor modulates mitochondrial oxidant stress in acetaminophen hepatotoxicity. Toxicol Sci 2011;122(02):598-605

87 Norberg E, Orrenius S, Zhivotovsky B. Mitochondrial regulation of cell death: processing of apoptosis-inducing factor (AIF). Biochem Biophys Res Commun 2010;396(01):95-100

88 Ni HM, Bockus A, Boggess N, Jaeschke H, Ding WX. Activation of autophagy protects against acetaminophen-induced hepatotoxicity. Hepatology 2012;55(01):222-232

$89 \mathrm{Ni} \mathrm{HM}$, Williams JA, Jaeschke H, Ding WX. Zonated induction of autophagy and mitochondrial spheroids limits acetaminopheninduced necrosis in the liver. Redox Biol 2013;1:427-432

90 Baulies A, Ribas V, Núñez S, et al. Lysosomal cholesterol accumulation sensitizes to acetaminophen hepatotoxicity by impairing mitophagy. Sci Rep 2015;5:18017

91 Du K, Ramachandran A, McGill MR, et al. Induction of mitochondrial biogenesis protects against acetaminophen hepatotoxicity. Food Chem Toxicol 2017;108(Pt A):339-350

92 Uzi D, Barda L, Scaiewicz V, et al. CHOP is a critical regulator of acetaminophen-induced hepatotoxicity. J Hepatol 2013;59(03): 495-503

93 Wang X, Thomas B, Sachdeva R, et al. Mechanism of arylating quinone toxicity involving Michael adduct formation and induction of endoplasmic reticulum stress. Proc Natl Acad Sci U S A 2006;103(10):3604-3609

94 Hur KY, So JS, Ruda V, et al. IRE1 $\alpha$ activation protects mice against acetaminophen-induced hepatotoxicity.J Exp Med 2012; 209(02):307-318

95 Lee DH, Lee B, Park JS, et al. Inactivation of Sirtuin2 protects mice from acetaminophen-induced liver injury: possible involvement of ER stress and S6K1 activation. BMB Rep 2018;pii:4170; [ Epub ahead of print]

96 Huo Y, Yin S, Yan M, et al. Protective role of p53 in acetaminophen hepatotoxicity. Free Radic Biol Med 2017;106:111-117

97 Sun J, Wen Y, Zhou Y, et al. p53 attenuates acetaminopheninduced hepatotoxicity by regulating drug-metabolizing enzymes and transporter expression. Cell Death Dis 2018;9 (05):536

98 Borude P, Bhushan B, Gunewardena S, Akakpo J, Jaeschke H, Apte $\mathrm{U}$. Pleiotropic role of p53 in injury and liver regeneration after acetaminophen overdose. Am J Pathol 2018;188(06):1406-1418

99 Kass GE, Macanas-Pirard P, Lee PC, Hinton RH. The role of apoptosis in acetaminophen-induced injury. Ann N Y Acad Sci 2003;1010:557-559

100 Zhang YF, He W, Zhang C, et al. Role of receptor interacting protein (RIP) 1 on apoptosis-inducing factor-mediated necroptosis during acetaminophen-evoked acute liver failure in mice. Toxicol Lett 2014;225(03):445-453

101 Jaeschke H, Fisher MA, Lawson JA, Simmons CA, Farhood A, Jones DA. Activation of caspase 3 (CPP32)-like proteases is essential for TNF-alpha-induced hepatic parenchymal cell apoptosis and neutrophil-mediated necrosis in a murine endotoxin shock model. J Immunol 1998;160(07):3480-3486

102 Bajt ML, Lawson JA, Vonderfecht SL, Gujral JS, Jaeschke H. Protection against Fas receptor-mediated apoptosis in hepatocytes and nonparenchymal cells by a caspase- 8 inhibitor in vivo: evidence for a postmitochondrial processing of caspase-8. Toxicol Sci 2000;58(01):109-117

103 Gujral JS, Knight TR, Farhood A, Bajt ML, Jaeschke H. Mode of cell death after acetaminophen overdose in mice: apoptosis or oncotic necrosis? Toxicol Sci 2002;67(02):322-328
104 Lawson JA, Fisher MA, Simmons CA, Farhood A, Jaeschke $\mathrm{H}$. Inhibition of Fas receptor (CD95)-induced hepatic caspase activation and apoptosis by acetaminophen in mice. Toxicol Appl Pharmacol 1999;156(03):179-186

105 Jaeschke H, Cover C, Bajt ML. Role of caspases in acetaminopheninduced liver injury. Life Sci 2006;78(15):1670-1676

106 Jaeschke H, Duan L, Akakpo JY, Farhood A, Ramachandran A. The role of apoptosis in acetaminophen hepatotoxicity. Food Chem Toxicol 2018;118:709-718

107 Cao P, Sun J, Sullivan MA, et al. Angelica sinensis polysaccharide protects against acetaminophen-induced acute liver injury and cell death by suppressing oxidative stress and hepatic apoptosis in vivo and in vitro. Int J Biol Macromol 2018;111:1133-1139

108 Zhou YD, Hou JG, Liu W, et al. 20(R)-ginsenoside Rg3, a rare saponin from red ginseng, ameliorates acetaminophen-induced hepatotoxicity by suppressing PI3K/AKT pathway-mediated inflammation and apoptosis. Int Immunopharmacol 2018; 59:21-30

109 Vanden Berghe T, Kaiser WJ, Bertrand MJ, Vandenabeele P. Molecular crosstalk between apoptosis, necroptosis, and survival signaling. Mol Cell Oncol 2015;2(04):e975093

110 Dara L. The receptor interacting protein kinases in the liver. Semin Liver Dis 2018;38(01):73-86

111 Sun L, Wang H, Wang Z, et al. Mixed lineage kinase domain-like protein mediates necrosis signaling downstream of RIP3 kinase. Cell 2012;148(1-2):213-227

112 Wang H, Sun L, Su L, et al. Mixed lineage kinase domain-like protein MLKL causes necrotic membrane disruption upon phosphorylation by RIP3. Mol Cell 2014;54(01):133-146

113 Ramachandran A, McGill MR, Xie Y, Ni HM, Ding WX, Jaeschke H. Receptor interacting protein kinase 3 is a critical early mediator of acetaminophen-induced hepatocyte necrosis in mice. Hepatology 2013;58(06):2099-2108

114 Deutsch M, Graffeo CS, Rokosh R, et al. Divergent effects of RIP1 or RIP3 blockade in murine models of acute liver injury. Cell Death Dis 2015;6:e1759

$115 \mathrm{Li}$ JX, Feng JM, Wang Y, et al. The B-Raf(V600E) inhibitor dabrafenib selectively inhibits RIP3 and alleviates acetaminophen-induced liver injury. Cell Death Dis 2014;5:e1278

116 Dara L, Johnson H, Suda J, et al. Receptor interacting protein kinase 1 mediates murine acetaminophen toxicity independent of the necrosome and not through necroptosis. Hepatology 2015;62(06):1847-1857

117 Schneider AT, Gautheron J, Tacke F, Vucur M, Luedde T. Receptor interacting protein kinase 1 (RIPK1) in hepatocytes does not mediate murine acetaminophen toxicity. Hepatology 2016;64 (01):306-308

118 Maes M, Vinken M, Jaeschke H. Experimental models of hepatotoxicity related to acute liver failure. Toxicol Appl Pharmacol 2016;290:86-97

119 McGill MR, Williams CD, Xie Y, Ramachandran A, Jaeschke H. Acetaminophen-induced liver injury in rats and mice: comparison of protein adducts, mitochondrial dysfunction, and oxidative stress in the mechanism of toxicity. Toxicol Appl Pharmacol 2012;264(03):387-394

120 Kučera O, Endlicher R, Rychtrmoc D, Lotková H, Sobotka O, Červinková Z. Acetaminophen toxicity in rat and mouse hepatocytes in vitro. Drug Chem Toxicol 2017;40(04):448-456

121 Ackerman Z, Skarzinski G, Link G, Glazer M, Pappo O, Grozovski M. The effects of chronic iron overload in rats with acute acetaminophen overdose. Toxicol Pathol 2018;46(05):597-607

122 Westerink WM, Schoonen WG. Cytochrome P450 enzyme levels in HepG2 cells and cryopreserved primary human hepatocytes and their induction in HepG2 cells. Toxicol In Vitro 2007;21(08): 1581-1591

123 Rogue A, Lambert C, Spire C, Claude N, Guillouzo A. Interindividual variability in gene expression profiles in human 
hepatocytes and comparison with HepaRG cells. Drug Metab Dispos 2012;40(01):151-158

124 McGill MR, Yan HM, Ramachandran A, Murray GJ, Rollins DE, Jaeschke H. HepaRG cells: a human model to study mechanisms of acetaminophen hepatotoxicity. Hepatology 2011;53(03): 974-982

125 Xie Y, McGill MR, Dorko K, et al. Mechanisms of acetaminopheninduced cell death in primary human hepatocytes. Toxicol Appl Pharmacol 2014;279(03):266-274

126 McGill MR, Sharpe MR, Williams CD, Taha M, Curry SC, Jaeschke $\mathrm{H}$. The mechanism underlying acetaminophen-induced hepatotoxicity in humans and mice involves mitochondrial damage and nuclear DNA fragmentation. J Clin Invest 2012;122(04): 1574-1583

127 Harrill AH, Ross PK, Gatti DM, Threadgill DW, Rusyn I. Population-based discovery of toxicogenomics biomarkers for hepatotoxicity using a laboratory strain diversity panel. Toxicol Sci 2009;110(01):235-243

128 Duan L, Davis JS, Woolbright BL, et al. Differential susceptibility to acetaminophen-induced liver injury in sub-strains of C57BL/ 6 mice: 6N versus 6J. Food Chem Toxicol 2016;98(Pt B):107-118

129 Du K, Williams CD, McGill MR, Jaeschke H. Lower susceptibility of female mice to acetaminophen hepatotoxicity: Role of mitochondrial glutathione, oxidant stress and c-jun $\mathrm{N}$-terminal kinase. Toxicol Appl Pharmacol 2014;281(01):58-66

130 Masubuchi Y, Nakayama J, Watanabe Y. Sex difference in susceptibility to acetaminophen hepatotoxicity is reversed by buthionine sulfoximine. Toxicology 2011;287(1-3):54-60

131 Davern TJ II, James LP, Hinson JA, et al; Acute Liver Failure Study Group. Measurement of serum acetaminophen-protein adducts in patients with acute liver failure. Gastroenterology 2006;130 (03):687-694

132 James LP, Letzig L, Simpson PM, et al. Pharmacokinetics of acetaminophen-protein adducts in adults with acetaminophen overdose and acute liver failure. Drug Metab Dispos 2009;37 (08):1779-1784

133 Roberts DW, Lee WM, Hinson JA, et al. An immunoassay to rapidly measure acetaminophen protein adducts accurately identifies patients with acute liver injury or failure. Clin Gastroenterol Hepatol 2017;15(04):555-562.e3

134 Wong SG, Card JW, Racz WJ. The role of mitochondrial injury in bromobenzene and furosemide induced hepatotoxicity. Toxicol Lett 2000;116(03):171-181

135 Jaeschke H, McGill MR, Ramachandran A. Oxidant stress, mitochondria, and cell death mechanisms in drug-induced liver injury: lessons learned from acetaminophen hepatotoxicity. Drug Metab Rev 2012;44(01):88-106

136 Antoine DJ, Jenkins RE, Dear JW, et al. Molecular forms of HMGB1 and keratin-18 as mechanistic biomarkers for mode of cell death and prognosis during clinical acetaminophen hepatotoxicity. J Hepatol 2012;56(05):1070-1079

137 McGill MR, Staggs VS, Sharpe MR, Lee WM, Jaeschke H; Acute Liver Failure Study Group. Serum mitochondrial biomarkers and damage-associated molecular patterns are higher in acetaminophen overdose patients with poor outcome. Hepatology 2014;60 (04):1336-1345

138 Weerasinghe SV, Jang YJ, Fontana RJ, Omary MB. Carbamoyl phosphate synthetase- 1 is a rapid turnover biomarker in mouse and human acute liver injury. Am J Physiol Gastrointest Liver Physiol 2014;307(03):G355-G364

139 Chen C, Krausz KW, Shah YM, Idle JR, Gonzalez FJ. Serum metabolomics reveals irreversible inhibition of fatty acid betaoxidation through the suppression of PPARalpha activation as a contributing mechanism of acetaminophen-induced hepatotoxicity. Chem Res Toxicol 2009;22(04):699-707

140 McGill MR, Li F, Sharpe MR, et al. Circulating acylcarnitines as biomarkers of mitochondrial dysfunction after acetaminophen overdose in mice and humans. Arch Toxicol 2014;88(02): 391-401

141 Saito C, Zwingmann C, Jaeschke H. Novel mechanisms of protection against acetaminophen hepatotoxicity in mice by glutathione and N-acetylcysteine. Hepatology 2010;51(01): 246-254

142 Bhattacharyya S, Yan K, Pence L, et al. Targeted liquid chromatography-mass spectrometry analysis of serum acylcarnitines in acetaminophen toxicity in children. Biomarkers Med 2014;8 (02):147-159

143 Antoine DJ, Williams DP, Kipar A, et al. High-mobility group box1 protein and keratin-18, circulating serum proteins informative of acetaminophen-induced necrosis and apoptosis in vivo. Toxicol Sci 2009;112(02):521-531

144 Wang K, Zhang S, Marzolf B, et al. Circulating microRNAs, potential biomarkers for drug-induced liver injury. Proc Natl Acad Sci U S A 2009;106(11):4402-4407

145 Starkey Lewis PJ, Dear J, Platt V, et al. Circulating microRNAs as potential markers of human drug-induced liver injury. Hepatology 2011;54(05):1767-1776

146 Bhushan B, Walesky C, Manley M, et al. Pro-regenerative signaling after acetaminophen-induced acute liver injury in mice identified using a novel incremental dose model. Am J Pathol 2014;184(11):3013-3025

147 Schmidt LE, Dalhoff K. Alpha-fetoprotein is a predictor of outcome in acetaminophen-induced liver injury. Hepatology 2005; 41(01):26-31

148 Ohtomi M, Nagai H, Ohtake H, Uchida T, Suzuki K. Dynamic change in expression of LECT2 during liver regeneration after partial hepatectomy in mice. Biomed Res 2007;28(05):247-253

149 Sato Y, Watanabe H, Kameyama H, et al. Serum LECT2 level as a prognostic indicator in acute liver failure. Transplant Proc 2004; 36(08):2359-2361

150 Borude PC, Brimacombe MB, Jaeschke H, Apte U, Lee WM. Leukocyte cell derived chemotaxin-2 as biomarker of liver regeneration after acute liver failure [abstract]. Hepatology 2015;62(Suppl 1):1073A

151 Church RJ, Kullak-Ublick GA, Aubrecht J, et al. Candidate biomarkers for the diagnosis and prognosis of drug-induced liver injury: An international collaborative effort. Hepatology 2019; 69(02):760-773

152 Dear JW, Antoine DJ, Starkey-Lewis P, Goldring CE, Park BK. Early detection of paracetamol toxicity using circulating liver microRNA and markers of cell necrosis. Br J Clin Pharmacol 2014;77 (05):904-905

153 Antoine DJ, Dear JW, Lewis PS, et al. Mechanistic biomarkers provide early and sensitive detection of acetaminophen-induced acute liver injury at first presentation to hospital. Hepatology 2013;58(02):777-787

154 Ward J, Kanchagar C, Veksler-Lublinsky I, et al. Circulating microRNA profiles in human patients with acetaminophen hepatotoxicity or ischemic hepatitis. Proc Natl Acad Sci U S A 2014;111(33):12169-12174

155 Vliegenthart AD, Shaffer JM, Clarke JI, et al. Comprehensive microRNA profiling in acetaminophen toxicity identifies novel circulating biomarkers for human liver and kidney injury. Sci Rep 2015;5:15501

156 Yang X, Salminen WF, Shi Q et al. Potential of extracellular microRNAs as biomarkers of acetaminophen toxicity in children. Toxicol Appl Pharmacol 2015;284(02):180-187

157 Weemhoff JL, Woolbright BL, Jenkins RE, et al. Plasma biomarkers to study mechanisms of liver injury in patients with hypoxic hepatitis. Liver Int 2017;37(03):377-384

158 Kubes P, Mehal WZ. Sterile inflammation in the liver. Gastroenterology 2012;143(05):1158-1172

159 Jaeschke H, Williams CD, Ramachandran A, Bajt ML. Acetaminophen hepatotoxicity and repair: the role of sterile inflammation and innate immunity. Liver Int 2012;32(01):8-20 
160 Woolbright BL, Jaeschke $\mathrm{H}$. Role of the inflammasome in acetaminophen-induced liver injury and acute liver failure. J Hepatol 2017;66(04):836-848

161 Lawson JA, Farhood A, Hopper RD, Bajt ML, Jaeschke H. The hepatic inflammatory response after acetaminophen overdose: role of neutrophils. Toxicol Sci 2000;54(02):509-516

162 Holt MP, Cheng L, Ju C. Identification and characterization of infiltrating macrophages in acetaminophen-induced liver injury. J Leukoc Biol 2008;84(06):1410-1421

163 Williams CD, Bajt ML, Sharpe MR, McGill MR, Farhood A, Jaeschke H. Neutrophil activation during acetaminophen hepatotoxicity and repair in mice and humans. Toxicol Appl Pharmacol 2014; 275(02):122-133

164 Antoniades CG, Quaglia A, Taams LS, et al. Source and characterization of hepatic macrophages in acetaminophen-induced acute liver failure in humans. Hepatology 2012;56(02):735-746

165 Jaeschke H. Mechanisms of liver injury. II. Mechanisms of neutrophil-induced liver cell injury during hepatic ischemiareperfusion and other acute inflammatory conditions. Am J Physiol Gastrointest Liver Physiol 2006;290(06):G1083-G1088

166 Jaeschke H. Reactive oxygen and mechanisms of inflammatory liver injury: present concepts. J Gastroenterol Hepatol 2011;26 (Suppl 1):173-179

167 James LP, McCullough SS, Knight TR, Jaeschke H, Hinson JA. Acetaminophen toxicity in mice lacking NADPH oxidase activity: role of peroxynitrite formation and mitochondrial oxidant stress. Free Radic Res 2003;37(12):1289-1297

168 Cover C, Liu J, Farhood A, et al. Pathophysiological role of the acute inflammatory response during acetaminophen hepatotoxicity. Toxicol Appl Pharmacol 2006;216(01):98-107

169 Williams CD, Bajt ML, Farhood A, Jaeschke H. Acetaminopheninduced hepatic neutrophil accumulation and inflammatory liver injury in CD18-deficient mice. Liver Int 2010;30(09):1280-1292

170 Dambach DM, Watson LM, Gray KR, Durham SK, Laskin DL. Role of CCR2 in macrophage migration into the liver during acetaminophen-induced hepatotoxicity in the mouse. Hepatology 2002; 35(05):1093-1103

171 You Q, Holt M, Yin H, Li G, Hu CJ, Ju C. Role of hepatic resident and infiltrating macrophages in liver repair after acute injury. Biochem Pharmacol 2013;86(06):836-843
172 Mossanen JC, Krenkel O, Ergen C, et al. Chemokine (C-C motif) receptor 2-positive monocytes aggravate the early phase of acetaminophen-induced acute liver injury. Hepatology 2016; 64(05):1667-1682

173 Liu ZX, Han D, Gunawan B, Kaplowitz N. Neutrophil depletion protects against murine acetaminophen hepatotoxicity. Hepatology 2006;43(06):1220-1230

174 Marques PE, Amaral SS, Pires DA, et al. Chemokines and mitochondrial products activate neutrophils to amplify organ injury during mouse acute liver failure. Hepatology 2012;56(05): 1971-1982

175 Woolbright BL, Jaeschke H. The impact of sterile inflammation in acute liver injury. J Clin Transl Res 2017;3(Suppl 1):170-188

176 Bourdi M, Masubuchi Y, Reilly TP, et al. Protection against acetaminophen-induced liver injury and lethality by interleukin 10: role of inducible nitric oxide synthase. Hepatology 2002;35 (02):289-298

177 Ryan PM, Bourdi M, Korrapati MC, et al. Endogenous interleukin4 regulates glutathione synthesis following acetaminopheninduced liver injury in mice. Chem Res Toxicol 2012;25(01): 83-93

178 Du K, Ramachandran A, Jaeschke H. Oxidative stress during acetaminophen hepatotoxicity: sources, pathophysiological role and therapeutic potential. Redox Biol 2016;10:148-156

179 Dear JW, Morrison E, Henriksen D, Nasstrom J. Calmangafodipir is a new treatment for late stage liver toxicity after acetaminophen overdose [abstract]. Hepatology 2017;66(Suppl 1): $4 \mathrm{~A}-5 \mathrm{~A}$

180 Akakpo JY, Ramachandran A, Kandel SE, et al. 4-Methylpyrazole protects against acetaminophen hepatotoxicity in mice and in primary human hepatocytes. Hum Exp Toxicol 2018;37(02): 1310-1322

181 Akakpo JY, Ramachandran A, Duan L, et al. 4-Methylpyrazole as new therapeutic for acetaminophen overdose in mice and in human hepatocytes [abstract]. Hepatology 2018;68 (Suppl 1):27A

$182 \mathrm{Kim} \mathrm{YH}$, Hwang JH, Kim KS, et al. Metformin ameliorates acetaminophen hepatotoxicity via Gadd $45 \beta$-dependent regulation of JNK signaling in mice. J Hepatol 2015;63(01): $75-82$ 